\title{
Non-penetrating phaco-deep sclerectomy with SkGel implantation — long-term observations
}

\author{
Katarzyna Lewczuk, Joanna Jabłońska, Jacek Rudowicz, Marek Rękas \\ Department of Ophthalmology, Military Institute of Medicine, Warsaw, Poland
}

\begin{abstract}
INTRODUCTION. The aim of this study is to present the efficacy and safety of non-penetrating phaco-deep sclerectomy (PDS) with implantation of an absorbable sodium hyaluronate implant (SkGel/Corneal).

MATERIALS AND METHODS. In a prospective case series study 219 procedures were performed on 176 subjects receiving PDS with SkGel implantation. Indications were uncontrolled primary-open angle glaucoma (POAG) and operable cataract. Data collected included best corrected visual acuity (BCVA), intraocular pressure (IOP), and number of hypotensive medications. Follow-up examinations were performed one and seven days after procedure, then one, three, and six months after, and thereafter every six months. Complete and qualified success (without and with hypotensive medications) was assessed for IOP $\leq 18 \mathrm{~mm} \mathrm{Hg}$ and IOP $\leq 12 \mathrm{~mm} \mathrm{Hg}$.

RESULTS. The mean follow-up was $48.3 \pm 12.8$ months. At 24 months, mean IOP decreased from $19.9 \pm 5.0 \mathrm{~mm}$ Hg to $13.4 \pm 3.1 \mathrm{~mm} \mathrm{Hg}(P<0.001)$ (31.8\% reduction) and to $13.3 \pm 2.7 \mathrm{~mm} \mathrm{Hg}(P=0.003)$ and after 60 months (33.2\% reduction). At the 24-month follow-up, the average number of anti-glaucoma medications was reduced from $2.3 \pm 0.8$ to $0.62 \pm 0.88(\mathrm{p}<0.001)$. Complete and qualified success rates for IOP $\leq 18 \mathrm{~mm} \mathrm{Hg}$ were $70.1 \%$ and $93.0 \%$, respectively. Goniopuncture $(23.8 \%)$, suturolysis $(20.1 \%)$, and needling (18.3\%) were performed. The most common complication was transient hypotony (36.07\%).

CONCLUSIONS. PDS with SkGel leads to an effective decrease in IOP over a long-term follow-up. The profile of the complications indicates that it is a safe procedure.
\end{abstract}

KEY WORDS: non-penetrating phaco-deep sclerectomy, SkGel implant, primary open angle glaucoma, cataract surgery

Ophthalmol J 2016; Vol. 1, No. 4, 115-123

\section{INTRODUCTION}

Non-penetrating deep sclerectomy (DS) avoids full thickness perforation of the anterior chamber, thus minimising the risk of complications encountered in classical trabeculectomy [1, 2]. Upon creation of a deep scleral flap, the external wall of Schlemm's canal is exposed [3]. In order to de-roof the Schlemm's canal wall, thus allowing aqueous humour to percolate through the semi-permeable trabeculo-Descemet's membrane (TDM) into the intrascleral lake. Here, prolonged absorption of aqueous humour filtered from the anterior chamber through the created TDM takes place [3-5].
This controlled percolation of aqueous humour from the anterior chamber results in intraocular pressure (IOP) reduction, while limiting excessive filtration to a certain extent, enough to prevent the onset of hypotony [3]. The precise mechanism of DS action is not yet fully known, but it seems that the newly created intrascleral space and relieving the collapse of Schlemm's canal are of key importance to aqueous humour percolation through the collector channels near the limbus [5]. Various scleral implants are used to stabilise the scleral lake, but the superiority of DS in combination with these implants compared to the classical procedure leaves no doubt at this time [6-10]. 
The objective of this study is to present the efficacy and safety of PDS with implantation of an absorbable sodium hyaluronate implant (SkGel/Corneal) in POAG with co-existing cataract based on long-term follow-up.

\section{MATERIALS AND METHODS}

This prospective case series study was approved by the Bioethics Committee of the Military Institute of Medicine in Warsaw, and every patient participating in the study gave written consent to the procedure a nd follow up.

The indication for surgical treatment was primary-open angle glaucoma (POAG) refractory to maximum medical tolerable therapy with anti-glaucoma medications, without satisfactory IOP control (IOP $\geq 18 \mathrm{~mm} \mathrm{Hg}$ ) or progression and changes to the visual field as well as co-existing cataract.

Exclusion criteria: secondary glaucoma, inability to provide consent to procedure, previous incisional glaucoma surgery, laser trabeculoplasty, pregnancy, and breastfeeding period. An improperly prepared TDM intraoperative also disqualified the subject from the study.

Follow-up examinations included measurement of IOP with Goldmann applanation tonometry, evaluation of the anterior and posterior segments of the eye, and careful evaluation of post-operative complications. The number of glaucoma medications used and the type and frequency of post-operative procedures to re-stablish drainage paths were analysed. BCVA was tested on a Snellen chart and then converted to the logMAR scale. The schedule of visits included a pre-operative baseline exam, surgery, post-operative visits on days one and seven, then months one, three, six, and 12 , and then every six months.

All surgical procedures were carried out by a single surgeon (MR) using the previously described technique [8]. First the conjunctiva was separated from the corneal limbus, then a $5 \times 5 \mathrm{~mm}$ surface scleral flap as thin as possible was created, with its base in the limbus area. Using the modified method of Bellucci et al. [11], a $3.5 \times 3.5 \times 0.75 \mathrm{~mm}$, piece of sclera was excised in the deep layer of the sclera approaching the scleral spur. The next stage of the procedure, phacoemulsification, was performed through a temporal clear corneal incision, $2.6 \mathrm{~mm}$ in width, and a flexible intraocular lens implant was inserted into the anterior chamber (SA30AT, SA60AT, SN60AT, SN60WF - Alcon Laborato- ries). In the final step of the procedure, Schlemm's canal and Descemet's membrane were exposed up to Schwalbe's line, and a deep scleral flap up to Schwalbe's line in the exterior wall of Schlemm's canal was removed (Fig. 1A). Next, the SkGel implant (Corneal) was inserted into the scleral bed (Fig. 1B), and the surface flap and wound in the conjunctiva were closed.

Symptoms of inflammation and fibrosis of the filtering bleb were treated with fluorouracil (5-FU) subconjunctivally $(5 \mathrm{mg}, 0.1 \mathrm{~mL})$ injected daily for five consecutive days, and this was repeated when necessary after one week. In cases where good IOP regulation was achieved antimetabolites were discontinued, or when a typical complication occurred [8]. At the same time, suturolysis of one or two sutures of the scleral flap were performed using an argon laser $(50 \mu \mathrm{m}, 800-1000 \mathrm{~mW}, 100 \mathrm{~ms})$. In the case of increased IOP ( $>15 \mathrm{~mm} \mathrm{Hg}$ ), caused by failure of the filtering membrane (lack of or poorly developed filtering bleb), goniopuncture was performed (TDM perforation) using an Nd:YAG laser $(2-4 \mathrm{~mJ}$, 2-15 impulses) [7]. If IOP lowering was not sufficient, delicate eye massage was applied. Superficial needling was applied when Tennon's encapsulation occurred while filtration under the flap was observed. Deep needling, however, was performed after UBM examination demonstrated the presence of a scleral lake and absence of the filtering bleb. All patients received a topical steroid in combination with an antibiotic (dexamethasone, neomycin, polymyxin B).

Complete success was defined as IOP $\leq 18 \mathrm{~mm}$ $\mathrm{Hg}$ without anti-glaucoma medications and qualified success as IOP $\leq 18 \mathrm{~mm} \mathrm{Hg}$ with and without anti-glaucoma medications [12]. The same was done for the IOP $\leq 12 \mathrm{~mm} \mathrm{Hg}$. The procedure was recognised as a failure if IOP was above $18 \mathrm{~mm} \mathrm{Hg}$ with anti-glaucoma medications, the need for second glaucoma surgery, or loss of light perception.

Post-operative complications were divided into early (up to one week after surgery) and later (more than one week after surgery). Hypotony was recognised if IOP $\leq 6 \mathrm{~mm} \mathrm{Hg}$ persisted longer than one week; IOP > $18 \mathrm{~mm} \mathrm{Hg}$ within the first week post-surgery was considered elevated [13]. Shallowing of the chamber, displacement of the anterior chamber, leaks in the filtering bleb, detachment of the choroid, anterior chamber hyphaemia, 3 or $4+$ of Tyndall effect, and haemorrhagic choroidal detachment were defined according to previously described definitions $[7,13]$. Deterioration of vision was recognised by loss of BCVA by 2 lines or more, 

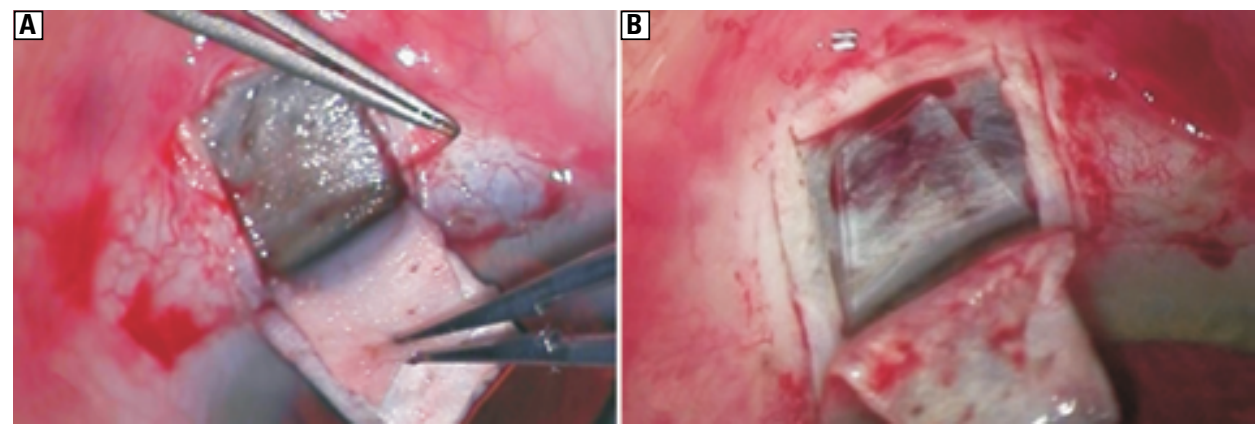

FIGURE 1. Non-penetrating deep sclerectomy. Making of the trabeculo-Descemet's membrane (A); SkGel/Corneal in decompression space (B)

\begin{tabular}{|l|c|}
\hline \multicolumn{2}{|l|}{ Table 1. Patients' demographic data } \\
\hline Demographic data & Mean (SD) \\
\hline Observation period (months) & $48.3 \pm 12.8$ \\
\hline Age (years) & $77.4 \pm 11.9$ \\
\hline Patients (number) & 176 \\
\hline Female & 99 \\
\hline Male & 77 \\
\hline Eyes (number) & 219 \\
\hline Right & 109 \\
\hline Left & 110 \\
\hline SD - standard deviation & \\
\hline
\end{tabular}

and persisting for more than three months after surgery. Statistical processing was carried out according to the World Glaucoma Association Guidelines on Design and Reporting of Glaucoma Surgical Trials [13].

Statistical analysis was conducted by means of Shapiro-Wilk W-test and Levene's test, as well as Wilcoxon's signed rank test and Friedman's ANOVA. Survival analysis was conducted using the Kaplan-Meier method and the log rank test. Research material was gathered in a database created in Access, then prepared in Excel from the Microsoft Office Professional 2010 package. Statistica PL 10.0 (StatSoft Polska) software was used for statistical calculations and creating charts.

\section{RESULTS}

\section{DEMOGRAPHIC DATA}

The study encompassed 219 eyes in 176 subjects with POAG and cataract. Demographic data are presented in Table 1.

\section{INTRAOCULAR PRESSURE CONTROL}

Pre-operative baseline mean IOP was $19.9 \pm 5.0 \mathrm{~mm} \mathrm{Hg}$ and was reduced by $52.5 \%$ on the first day to $8.5 \pm 4.9 \mathrm{~mm} \mathrm{Hg}(P<0.001)$. Mean IOP stabilised up to one month post-surgery and was not subject to statistically significant change until the end of the observation period $(P=0.39397)$. After 12 months of post-operative follow-up the mean IOP was $12.7 \pm 3.5 \mathrm{~mm} \mathrm{Hg}$, and after 24 months, $13.4 \pm 3.1 \mathrm{~mm} \mathrm{Hg}$, which was a reduction of mean IOP by $35.4 \%(P<0.001)$ and by $31.8 \%(P<0.001)$, respectively. At the end of the post-operative observation period $\left(60^{\text {th }}\right.$ month), an IOP of $13.3 \pm 2.7 \mathrm{~mm} \mathrm{Hg}(P=0.003)$ was achieved, which resulted in $33.2 \%$ reduction. (Fig. 2, Tab. 2).

\section{MEDICATIONS}

The mean number of anti-glaucoma medications was reduced from $2.3 \pm 0.8$ to $0.3 \pm 0.7$ after 12 months and to $0.6 \pm 0.9$ after the $24^{\text {th }}$ month post-surgery $(P<0.001)$. The mean number of anti-glaucoma medications gradually increased from $0.01 \pm 0.15$ on the first day to $1.18 \pm 1.33$ at the end of follow-up (Tab. 2).

\section{SURGICAL SUCCESS}

Complete success for the target IOP $\leq 18 \mathrm{~mm}$ $\mathrm{Hg}$ criterion at the 12 and 24 months was achieved in $90.5 \%$ and in $70.1 \%$ of cases, respectively. For IOP $\leq 12 \mathrm{~mm} \mathrm{Hg}$, the complete success rate was lower, amounting to $71.2 \%$ at 12 months and $43.7 \%$ at 24 months. The complete success rate for the IOP $\leq 18 \mathrm{~mm} \mathrm{Hg}$ decreased over time and reached $39.8 \%$ after 36 months, $27.7 \%$ after 48 months, and $12.0 \%$ after 60 months, and the rate for the target IOP $\leq 12 \mathrm{~mm} \mathrm{Hg}$ reached 19.3\%, $12.0 \%$, and $3.4 \%$, respectively. Qualified success for the IOP $\leq 18 \mathrm{~mm} \mathrm{Hg}$ criterion after 12 and 24 months was achieved in $97.3 \%$ and $93.0 \%$ of cases, respectively, and for the target IOP $\leq 12 \mathrm{~mm} \mathrm{Hg}$ criterion, in $73.8 \%$ and $49.3 \%$ of cases, respectively. 


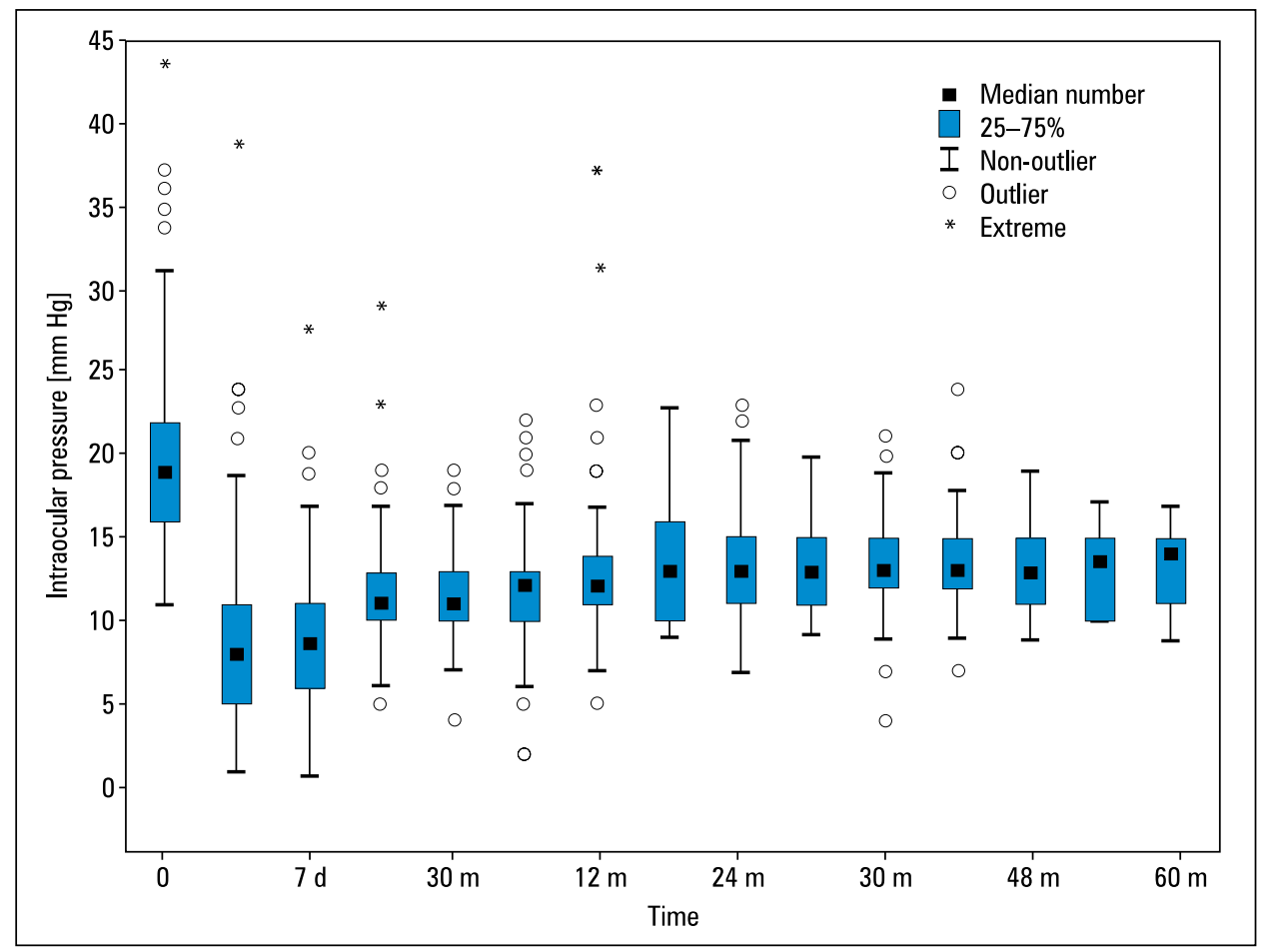

FIGURE 2. Intraocular pressure values at specific times after surgery

\begin{tabular}{|c|c|c|c|c|c|c|}
\hline \multirow[t]{2}{*}{ Time } & \multicolumn{3}{|c|}{ Intraocular pressure [mm Hg] } & \multicolumn{3}{|c|}{ Medications ( $n$ ) } \\
\hline & $\begin{array}{c}\text { Mean } \\
\text { (SD) }\end{array}$ & Median & Range & $\begin{array}{c}\text { Mean } \\
\text { (SD) }\end{array}$ & Median & Range \\
\hline Pre-op & $19.9 \pm 5.0$ & 19 & $11-43$ & $2.3 \pm 0.8$ & 2 & $1-5$ \\
\hline $1^{\text {st }}$ day & $8.5 \pm 4.9$ & 8 & $1-39$ & $0.01 \pm 0.2$ & 0 & $0-2$ \\
\hline $7^{\text {th }}$ day & $9.0 \pm 4.1$ & 9 & $1-27$ & $0.01 \pm 0.2$ & 0 & $0-2$ \\
\hline $1^{\text {st }}$ month & $11.8 \pm 3.1$ & 11 & $5-29$ & $0.1 \pm 0.3$ & 0 & $0-2$ \\
\hline $6^{\text {th }}$ month & $11.9 \pm 2.9$ & 12 & $2-22$ & $0.2 \pm 0.5$ & 0 & $0-2$ \\
\hline $12^{\text {th }}$ month & $12.7 \pm 3.5$ & 12 & $5-37$ & $0.3 \pm 0.7$ & 0 & $0-4$ \\
\hline $18^{\text {th }}$ month & $13.5 \pm 3.1$ & 13 & $9-23$ & $0.4 \pm 0.7$ & 0 & $0-3$ \\
\hline $24^{\text {th }}$ month & $13.4 \pm 3.1$ & 13 & $7-23$ & $0.6 \pm 0.9$ & 0 & $0-4$ \\
\hline $36^{\text {th }}$ month & $13.5 \pm 3.0$ & 13 & $4-21$ & $0.9 \pm 0.9$ & 1 & $0-3$ \\
\hline $48^{\text {th }}$ month & $13.2 \pm 2.5$ & 13 & $9-19$ & $1.0 \pm 0.9$ & 1 & $0-3$ \\
\hline $60^{\text {th }}$ month & $13.3 \pm 2.7$ & 14 & $9-17$ & $1.2 \pm 1.3$ & 1 & $0-3$ \\
\hline
\end{tabular}

$\mathrm{SD}-$ standard deviation; $\mathrm{n}-$ number of medications

Qualified success for the target IOP $\leq 18 \mathrm{~mm} \mathrm{Hg}$ criterion was achieved in $86.6 \%$ of cases after 36 months, $85.4 \%$ after 48 months, and $81.2 \%$ after 60 months, and for the target IOP $\leq 12 \mathrm{~mm} \mathrm{Hg}$ criterion, the qualified success rate reached $25.7 \%$, $17.9 \%$, and $8.5 \%$, respectively (Fig. 3 ).

IOP below $18 \mathrm{~mm} \mathrm{Hg}$ was achieved in 90.4\% of cases after 24 months. IOP reduction by at least $30 \%$ relative to initial values was achieved in $63.1 \%$ of eyes after 24 months (Fig. 4).

\section{ADDITIONAL PROCEDURES}

5-FU injections were applied in 70 eyes (38.9\%). The average 5-FU dose was $19.7 \pm 12.7 \mathrm{mg}(5-75)$ at an average injection dose of $3.9 \pm 2.5 \mathrm{mg}(1-15)$. The average time until commencement of 5-FU therapy was $17.8 \pm 10.4$ days after surgery (2-44 days).

Goniopuncture was performed in 52 eyes (23.7\%), and suturolysis was performed in 44 cases $(20.1 \%)$. Suturolysis and goniopuncture were per- 


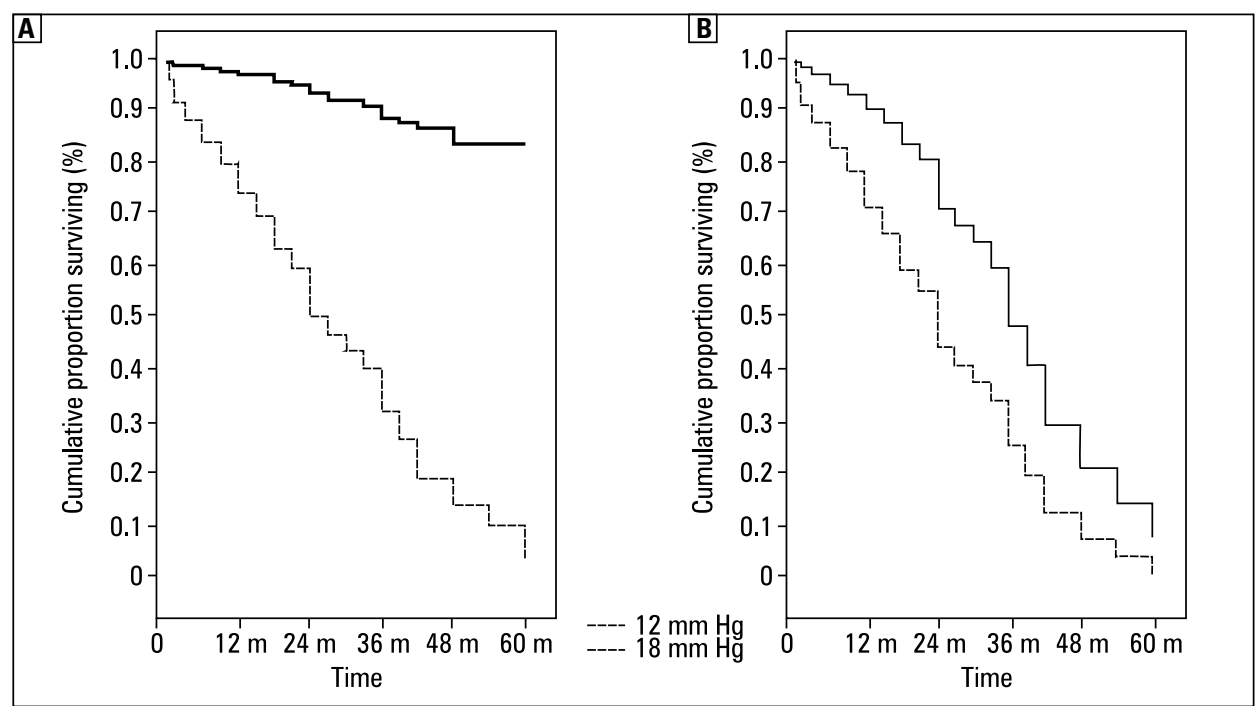

FIGURE 3. Cumulative proportion surviving for 12 and $18 \mathrm{~mm} \mathrm{Hg}$ criteria: qualified success rate (A); complete success rate (B)

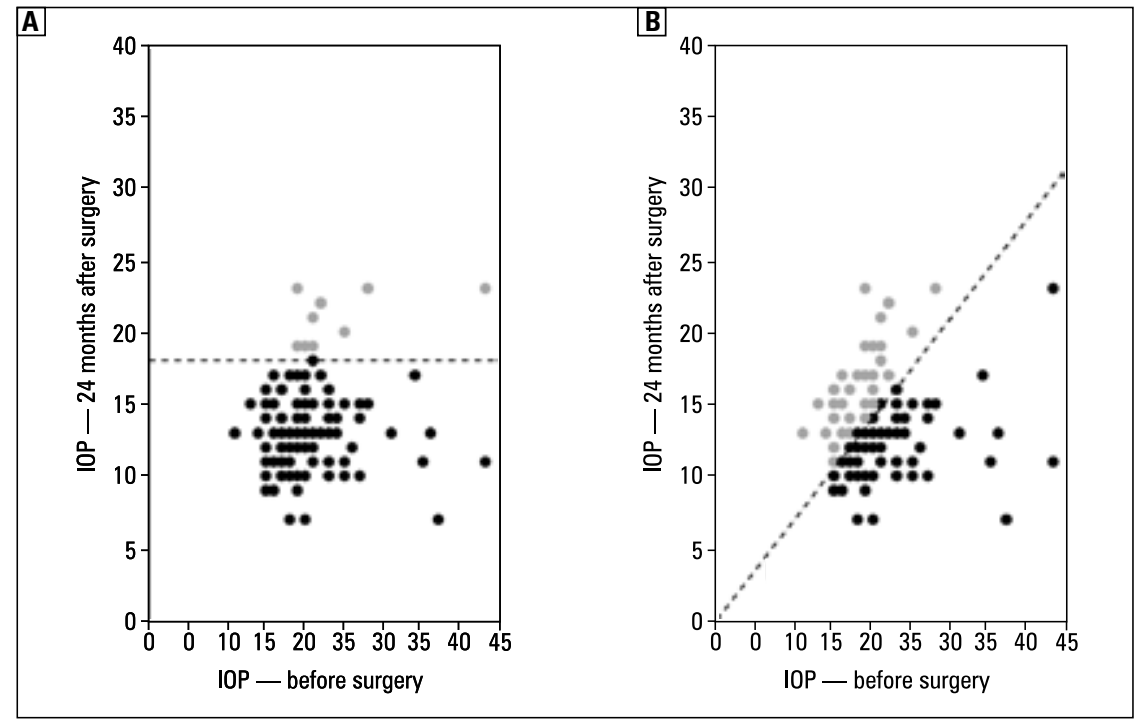

FIGURE 4. Scatter plot: $x$ axis - intraocular pressure before surgery and y axis -24 months after surgery: $\operatorname{IOP} \leq 18.0 \mathrm{~mm} \mathrm{Hg}(\mathbf{A})$; IOP reduction $\geq 30 \%$ (B)

formed concurrently in 34 cases $(15.6 \%)$. Needling was performed in 40 eyes ( $18.3 \%$ of all cases).

\section{CORRECTED DISTANCE VISUAL ACUITY}

Mean $\log$ MAR of BCVA improved from $0.3 \pm 0.3$ before surgery to $0.1 \pm 0.2$ after 24 months $(P<0.001)$. On day 1 after surgery, there was a slight decrease of BCVA to $0.4 \pm 0.3$, but on day 7 it improved to $0.3 \pm 0.3$. On day 30, BCVA reached $0.1 \pm 0.2$ and stabilised until the end of the observation period $(P=0.753)$ (Tab. 3).
At month 24 post-surgery, BCVA was lower by 0.5 in $20.2 \%$ of cases and higher by 0.5 in $79.8 \%$ of cases. BCVA above 0.8 was achieved in $53.9 \%$ of treated eyes. Loss of two or more lines of vision on the Snellen chart was observed in four eyes $(1.8 \%)$ after 12 months and in six eyes $(2.7 \%)$ after 24 months.

\section{COMPLICATIONS}

Transitory hypotony occurred in 79 eyes $(36.1 \%$ of cases) and was the most frequent post-operative 
Table 3. Mean values of best corrected distant visual acuity at specific times after surgery

Best corrected distance visual acuity (logMAR)

\begin{tabular}{|l|c|c|c|}
\hline Time & Mean (SD) & Range & $P^{*}$ \\
\hline Pre-op & $0.3 \pm 0.3$ & $0-1$ & \\
\hline $1^{\text {st }}$ day & $0.4 \pm 0.3$ & $0-1$ & 0.026 \\
\hline $7^{\text {th }}$ day & $0.3 \pm 0.3$ & $0-1$ & 0.019 \\
\hline $1^{\text {st }}$ month & $0.1 \pm 0.2$ & $0-1$ & $<0.001$ \\
\hline $6^{\text {th }}$ month & $0.1 \pm 0.2$ & $0-0.8$ & $<0.001$ \\
\hline $12^{\text {th }}$ month & $0.1 \pm 0.1$ & $0-0.5$ & $<0.001$ \\
\hline $18^{\text {th }}$ month & $0.1 \pm 0.2$ & $0-0.7$ & $<0.001$ \\
\hline $24^{\text {th }}$ month & $0.1 \pm 0.2$ & $0-0.7$ & $<0.001$ \\
\hline $36^{\text {th }}$ month & $0.2 \pm 0.1$ & $0-0.5$ & 0.065351 \\
\hline $48^{\text {th }}$ month & $0.2 \pm 0.3$ & $0-1$ & 0.206 \\
\hline
\end{tabular}

SD — standard deviation; logMAR — logarithm of the minimum angle of resolution; *Wilcoxon matched pairs test; ^ Friedman ANOVA, $\chi^{2} \mathrm{ANOVA}=8,790698$

Table 4. Post-operative complications

\begin{tabular}{|l|l|l|}
\hline Post-operative complications & $\mathbf{n}$ & $\%$ \\
\hline Harly & 79 & 36.1 \\
\hline Hypotony & 16 & 7.3 \\
\hline Corneal oedema & 12 & 5.5 \\
\hline Blood in the vicinity of the filtering bleb & 9 & 4.1 \\
\hline Serous choroidal detachment & 8 & 3.7 \\
\hline Leaking filtering bleb & 6 & 2.7 \\
\hline Inflammatory cells in anterior chamber & 5 & 2.3 \\
\hline Intraocular pressure rise & 4 & 1.8 \\
\hline Hyphaemia & 2 & 0.9 \\
\hline Orbital haematoma & 1 & 0.5 \\
\hline Late & & \\
\hline Bleb fibrosis & 48 & 21.9 \\
\hline Epitheliopathy & 25 & 11.4 \\
\hline Erosion of corneal epithelium & 10 & 4.6 \\
\hline Choroidal membrane & 7 & 3.2 \\
\hline Posterior synechia & 5 & 2.3 \\
\hline Cystoid macular oedema & 5 & 2.3 \\
\hline Posterior capsule opacification & 3 & 1.4 \\
\hline Macular haemorrhage & 2 & 0.9 \\
\hline Peripheral ulcerative keratitis & 1 & 0.5 \\
\hline Delamination of equatorial retina & 1 & 0.5 \\
\hline Transitory astigmatism after 5-FU therapy & 1 & 0.5 \\
\hline Dellen & 1 & 0.5 \\
\hline Haemorrhagic choroidal detachment & 1 & 0.5 \\
\hline Retinal tear & 1 & 0.5 \\
\hline Iris entrapment in the goniopuncture wound & 1 & 0.5 \\
\hline & & \\
\hline
\end{tabular}

complication. In one case $(0.4 \%)$, persistent hypotony lasted for three months. Shallowing of the anterior chamber occurred in 12 eyes (6.9\% of cases), and serous choroidal detachment occurred in eight cases (3.7\% of eyes). The most frequent onset of late post-operative complication was filtering bleb fibrosis in 48 eyes (21.9\%). After subconjunctival 5-FU injections, short-term corneal epithelium erosion occurred in 25 eyes (11.4\%) and transitory astigmatism in one eye $(0.5 \%)$. A compilation of post-operative complications is presented in Table 4.

\section{DISCUSSION}

DS reduces IOP by facilitating filtration of aqueous humour through the thin TDM that is left behind from the anterior chamber to the intrascleral decompression space, and from there to the subconjunctival space, suprachoroidal space, and trans-scleral path [4]. In order to improve the success rate of surgery, many authors apply post-operative procedures that improve the flow of aqueous humour $[1,7-9,14,15]$. To limit fibrosis of the filtration fistula we applied pre-operative 5-FU injections more frequently and at a mean dose higher than that encountered in the literature $[1,7-9,14,15]$. Only Reinthal et al. applied a greater injection dose [16]. The average dose of 5-FU was lower than that applied by Reinthal et al. [16]. In most studies, the percentage of injections falls within the range from 20 to $38 \%$, and in our study this percentage reached $38.9 \%[1,7,9,15,17]$.

Shaarawy et al. believe that goniopuncture should be recognised as part of the post-operative procedure after DS and that earlier goniopuncture is more effective over a long-term observation period $[14,18,19]$. We have applied goniopuncture somewhat less frequently than as described in the literature and we did not carry out prophylactic 
localised argon iridoplasty $[14,15,18-20]$. Iris incarceration into the scleral lake is observed as the most common complication after goniopuncture [20]. We noticed it in one eye only. The possible cause is that all our cases were combined with a phacoemulsification. Another reason could be the presence of SkGel, which occupies the scleral lake and prevents a sudden decompression. The subconjunctival outflow is the most important functional drainage pathway for aqueous humour in the first month after surgery, which is why we also applied eye massage after the performance of laser goniopuncture in this period [9]. Suturolysis is rarely applied after non-penetrating procedures [21]. In our observations, it was applied relatively often and generally in combination with goniopuncture in order to reduce resistance as much as possible on the route of aqueous humour drainage. Only Funnelli et al. reported a lower frequency of its application [21]. We combined post-operative needling with simultaneous 5-FU injection, similarly to Bissig et al. [22].

Guedes et al. did not observe a significant difference in the post-operative success rate between the non-penetrating procedure and its combination with phacoemulsification [23]. Average IOP reduction, both short-term and medium-term, achieved by other authors is comparable to the reduction achieved in our study [6, 24, 25]. Only long-term IOP reduction after 60 months was slightly lower in our study (33.2\%) than in the study by Galassi et al. (37.65\%) [18]. Application of mitomycin during surgery by Russo et al. did not have a significant effect on increasing the percentage of IOP reduction (38.3\%) [26]. Reduction of applied medications was similar to that seen in the study by Rebolleda et al. but lower than in the study by Galassi et al. [18, 24].

Post-operative BCVA is dependent on the rate of intra and post-operative complications as well as induced corneal astigmatism [27]. Shoji et al. showed that combining cataract surgery and non-penetrating surgery does not have a negative effect on post-operative BCVA in comparison with phacoemulsification by itself [28]. Our study shows, similarly as in the majority of other studies, that after a slight reduction in the initial post-operative period, the BCVA after DS returned to the baseline level after one week and stabilised around the third month [7-9, 14, 28, 29]. During the initial $24^{\text {th }}$ month observation period, the mean logMAR value of BCVA was $0.1 \pm 0.2$. A loss of two or more lines on the Snellen chart was observed in six eyes $(2.7 \%)$ after 24 months. Subretinal macular haemorrhage occurred in two eyes $(0.9 \%)$, folding of the premacular membrane occurred in two eyes $(0.9 \%)$, and chronic cystoid macular oedema occurred in two eyes $(0.9 \%)$.

The most frequent early complication was transitory hypotony (36.1\%). Other authors noted an equally quick disappearance of hypotony [7]. Moreover, on the first day after surgery, it was recognised by Shaarawy et al. as a positive factor in prognosis because it improved post-operative success and reduced the number of additional procedures stabilising drainage paths [30].

We observed inflammatory cells in a lower percentage (2.3\%) than other authors (27.29\%), which is the effect of preservation of the integrity of the anterior chamber $[1,31]$. Shaarawy et al. believe that a small amount of blood in the anterior chamber in the early post-operative period is probably the result of a blood reflux from the produced scleral bed [8]. Bleeding into the anterior chamber that ceased without consequence was observed in $0.9 \%$ of eyes. In most studies, bleeding into the anterior chamber does not exceed the teens in terms of percentage, and blood is quickly absorbed [9, 10, 21, 24].

Raised IOP in the early post-operative period occurred in $1.8 \%$ of cases; this percentage was lower than that encountered by other authors [30,32]. The application of goniopuncture and delicate eye massage made it possible to control IOP in three eyes; however, one case required the introduction of anti-glaucoma medications. In one eye, TDM rupture and iris entrapment requiring surgical intervention took place after goniopuncture.

We observed fibrosis of the filtering bleb at a similar rate of occurrence as did Mermoud et al. and Kozobolis et al. [1, 17]. Retinal delamination appeared in one patient, and equatorial retinal tearing occurred in another and was resolved by laser treatment. The low percentage of complications of this type after DS procedures is consistent with the results of other authors $[1,10,32]$.

Clouding of the posterior capsule requiring laser capsulotomy took place in three eyes (1.4\%). An extra-orbital haematoma occurred in one patient $(0.5 \%)$ during extra-orbital anaesthesia; however, it subsided without side effects.

\section{CONCLUSIONS}

Long-term follow-up demonstrate that non-penetrating phaco-deep sclerectomy with SkGel im- 
plantation combined with cataract surgery has the potential to achieve an effective reduction of IOP over the course of long-term follow-up. However, some of the early reduction diminished over time due to the progressing regeneration taking place in the sclera and episcleral space. The applied procedures for re-establishing drainage pathways are an integral component of post-operative care. These are necessary when aggressive healing limits the effect of the conducted surgery. The profile of the observed complications and significant improvement of visual acuity in the majority of eyes provide grounds for recognising non-penetrating deep sclerectomy as a safe procedure in patients with glaucoma and co-existing cataract.

\section{ACKNOWLEDGEMENTS}

This article was presented at the $6^{\text {th }}$ International Congress on Glaucoma Surgery ICGS 2012, Glasgow, Scotland, 13-15 September 2012; $17^{\text {th }}$ ESCRS Winter Meeting, Warsaw, Poland, 15-17 February 2013; $44^{\text {th }}$ Congress of Polish Society of Ophthalmology Warsaw, Poland, 13-15 June 2013; $7^{\text {th }}$ International Congress on Glaucoma Surgery ICGS 2014, Singapore, 20-22 February 2014.

\section{COMPLIANCE WITH ETHICAL STANDARDS}

All procedures performed in studies involving human participants were in accordance with the ethical standards of the institutional and/or national research committee and with the 1964 Helsinki Declaration and its later amendments or comparable ethical standards.

\section{INFORMED CONSENT}

Every subject participating in the study gave written consent to the procedure and follow-up care.

\section{FUNDING}

No funding was received for this research.

\section{CONFLICT OF INTEREST}

All authors certify that they have no affiliations with or involvement in any organisation or entity with any financial interest or non-financial interest in the subject matter or materials discussed in this manuscript.

\section{REFERENCES}

1. Mermoud A, Schnyder C, Sickenberg M, Chiou GY, Hédiguer S, Faggioni R. Comparison of deep sclerectomy with collagen implant and trabeculectomy in open-angle glaucoma. J Cataract Refract Surg 1999; 25: 323-331.

2. Rulli E, Biagioli E, Riva I et al. Efficacy and safety of trabeculectomy vs nonpenetrating surgical procedures: a systematic review and meta-analysis. JAMA Ophthalmol 2013; 131: 1573-1582.

3. Mermoud A, Ravinet E. Mechanisms of filtration in non-penetrating filtering surgeries. In: Non-penetrating glaucoma surgery. 1st ed. Martin Dunitz, London 2001: 57-65.

4. Marchini G, Marraffa M, Brunelli C, Morbio R, Bonomi L. Ultrasound biomicroscopy and intraocular-pressure-lowering mechanisms of deep sclerectomy with reticulated hyaluronic acid implant. J Cataract Refract Surg 2001; 27: 507-517.

5. Stegmanm R, Pienaar A, Miller D. Viscocanalostomy for open-angle glaucoma in black African patients. J Cataract Refract Surg 1999; 25: $316-322$.

6. D'Eliseo D, Pastena B, Longanesi L, Grisanti F, Negrini V. Comparison of deep sclerectomy with implant and combined glaucoma surgery. Ophthalmologica 2003; 217: 208-211.

7. Karlen ME, Sanchez E, Schnyder CC, Sickenberg M, Mermoud A. Deep sclerectomy with collagen implant: medium term results. $\mathrm{Br} J$ Ophthalmol 1999; 83: 6-11.

8. Shaarawy T, Karlen M, Schnyder C, Achache F, Sanchez E, Mermoud A. Five-year results of deep sclerectomy with collagen implant. J Cataract Refract Surg 2001; 27: 1770-1778.

9. Shaarawy T, Nguyen C, Schnyder C, Mermoud A. Comparative study between deep sclerectomy with and without collagen implant: long term follow up. Br J Ophthalmol 2004; 88: 95-98.

10. Sourdille P, Santiago PY, Villain F et al. Reticulated hyaluronic acid implant in nonperforating trabecular surgery. J Cataract Refract Surg 1999; 25: 332-339.

11. Bellucci $R$, Morselli $S$. Reverse flap dissection for glaucoma surgery. Ophthalmic Surg Lasers Imaging 2005; 36: 79-81.

12. Mousa AS. Preliminary evaluation of nonpenetrating deep sclerectomy with autologous scleral implant in open-angle glaucoma. Eye 2007; 21: 1234-1238.

13. Shaarawy TM, Sherwood MB, Grehn F. Guidelines on Design and Reporting of Glaucoma Surgical Trials. 2009.

14. Shaarawy T, Mansouri K, Schnyder C, Ravinet E, Achache F, Mermoud A. Long-term results of deep sclerectomy with collagen implant. J Cataract Refract Surg 2004; 30: 1225-1231.

15. Shaarawy T, Mansouri K, Schnyder C, Ravinet E, Achache F, Mermoud A. Long-term results of deep sclerectomy with collagen implant. J Cataract Refract Surg 2016; 30: 1225-1231.

16. Reinthal EK, Denk PO, Grüb M, Besch D, Bartz-Schmidt KU. Dose, timing and frequency of subconjunctival 5 -fluorouracil injections after glaucoma filtering surgery. Graefe's Arch Clin Exp Ophthalmol 2007; 245: 369-375.

17. Kozobolis VP, Christodoulakis EV., Tzanakis N, Zacharopoulos I, Pallikaris IG. Primary deep slerectomy versus primar deep sclerectomy with the use of mitomycin $C$ in primary open-angle glaucoma. $J$ Glaucoma 2002; 11: 287-293.

18. Galassi F, Giambene B. Deep sclerectomy with SkGel implant: 5-year results. J Glaucoma 2008; 17: 52-56.

19. Mermoud A, Karlen ME, Schnyder CC et al. Nd:Yag goniopuncture after deep sclerectomy with collagen implant. Oman J Ophthalmol 1999; 30: 120-125

20. Di Matteo F, Bettin P, Fiori M, Ciampi C, Rabiolo A, Bandello F. Nd:Yag laser goniopuncture for deep sclerectomy: efficacy and outcomes. Graefe's Arch Clin Exp Ophthalmol 2016; 254: 535-539.

21. Funnell CL, Clowes $M$, Anand N. Combined cataract and glaucoma surgery with mitomycin $\mathrm{C}$ : phacoemulsification-trabeculectomy compared to phacoemulsification-deep sclerectomy. Br J Ophthalmol 2005; 89: 694-698.

22. Bissig A, Rivier D, Zaninetti M, Shaarawy T, Mermoud A, Roy S. Ten years follow-up after deep sclerectomy with collagen implant. J Glaucoma 2008; 17: 680-686.

23. Guedes R, Guedes V, Chaoubah A. Phacoemulsification affect the long-term success of non-penetrating deep sclerectomy? Ophthalmic Surg Lasers Imaging Retina 2010; 41: 228-235. 
24. Rebolleda G, Muñoz-Negrete FJ. Comparison between phaco-deep sclerectomy converted into phaco-trabeculectomy and uneventful phaco-deep sclerectomy. Eur J Ophthalmol 2005; 15: 343-346.

25. Schreyger F, Scharioth G, Baatz H. SKGE ${ }^{\circledR}$ implant versus T-Flux ${ }^{\circledR}$ implant in the contralateral eye in deep sclerectomy with phacoemulsification: long-term follow-up. Open Ophthalmol J 2008; 2: 57-61.

26. Russo V, Scott IU, Stella A et al. Nonpenetrating deep sclerectomy with reticulated hyaluronic acid implant versus punch trabeculectomy: A prospective clinical trial. Eur J Ophthalmol 2008; 18: 751-757.

27. Claridge KG, Galbraith JK, Karmel V, Batesa K. The effect of trabeculectomy on refraction, keratometry and corneal topography. Eye (Lond) 1995; 9: 292-298.

28. Shoji T, Tanito $M$, Takahashi $H$ et al. Phacoviscocanalostomy versus cataract surgery only in patients with coexisting normal-tension glaucoma: midterm outcomes. J Cataract Refract Surg 2007; 33: 1209-1216.
29. Rekas M, Rudowicz J, Lewczuk K, Kluś A, Pawlik B, Stankiewicz A. Phacoemulsification-deep sclerectomy modified by trabeculum microperforations and implantation of lens anterior capsule as autologous scleral implant. Curr Med Res Opin 2010; 26: 2025-2032.

30. Shaarawy T, Flammer J, Smits G, Mermoud A. Low first postoperative day intraocular pressure as a positive prognostic indicator in deep sclerectomy. Br J Ophthalmol 2004; 88: 658-661.

31. Chiou AG, Mermoud A, Jewelewicz DA. Post-operative inflammation following deep sclerectomy with collagen implant versus standard trabeculectomy. Graefes Arch Clin Exp Ophthalmol 1998; 236: 593-596.

32. Gianoli F, Schnyder CC, Bovey E, Mermoud A. Combined surgery for cataract and glaucoma: Phacoemulsification and deep sclerectomy compared with phacoemulsification and trabeculectomy. J Cataract Refract Surg 1999; 25: 340-346. 